\title{
The regulation of cliff responses in the Mongolian gerbil (Meriones unguiculatus) by visual and tactual cues: I
}

A. COLLINS, G. LINDZEY, and D. D. THIESSEN, University of Texas, Austin, Tex. 78712

Before descending from a visual or tactual cliff, gerbils engage in orientations toward the floor. Descent never occurs until the animal touches the floor with its nose. On cliffs differing only in visual cues, latencies to descend were significantly lower from the shallow cliff. When the cliffs differed only in tactual cues, younger gerbils showed slight, and older animals much greater, discrimination. It is concluded that both visual and tactual cues regulate the descent response.

Thiessen, Lindzey, Blum, Tucker, \& Friend (1968) demonstrated a light-dark sensitivity in the Mongolian gerbil but found no clear-cut shallow-side preference on the visual cliff. They suggest that the latter result may have been due to either undetermined emotional factors or a visual deficit. This study attempts to minimize the effects of high emotionality by presenting shallow and deep stimuli on successive trials. Moreover, tactual cues may prevent the full expression of a visual capability. The primary aim of this study is to modify the test situation in such a way that tactual and visual cues can be studied independently and in combination. Although tactual cues are eliminated or controlled in the typical visual-cliff experiment, they have been shown to play a significant role in the descent response in hooded rats (Walk \& Gibson, 1961).

Preliminary qualitative observation indicates that tactual cues are also an important determinant of cliff descent in the gerbil. When placed on a small elevated platform gerbils engage in a relatively uniform sequence of behavior before descending. (1) First there are a number of "orientation responses" (ORs) which include flattening the body against the platform surface and extending the head over the edge and downward. Initial orientations are typically shallow (approximately $1 / 2$ in.) and become deeper with time on the platform. (2) If the animal descends, the initial shallow ORs are followed by deeper orientations until the nose (or vibrissae) touches the floor. (3) Actual descent rarely occurs unless the animal touches the floor with its nose; conversely, contact with the floor is rarely made without immediate descent. Descent involves lowering the forepaws to the floor without raising the head from the deep OR. The deepest $O R$ possible without falling from the platform is approximately 2 in. Virtually all ORs are completed in less than 2 sec. This description suggests an appetitive-consummatory analysis with orientation representing the appetitive response and the tactual verification and descent representing the consummatory response.

The following predictions follow from these possible processes:

(1) If the gerbil possesses visual depth discrimination and seeks visual cues during the OR, then latency to descend (LTD) to a visually patterned floor from a platform beyond reach of the initial shallow ORs, but within range of the deeper ORs (i.e., 1 to 2 in.), should be less than LTD from a platform presenting deeper visual cues(e.g. 10 in.). This difference should remain even when the same tactual cues are involved (achieved by placing a glass sheet 2 in. below the platform surface). The difference, however, should be reduced or eliminated if visual cues are minimized by the use of an unpatterned floor covering.

(2) If the gerbil seeks tactual cues, then the depth of the OR should lengthen and descent should occur to a surface within range of the OR, even in the absence of shallow visual ones. Thus, LTD from a high platform with a glass sheet 2 in. below the upper surface should be less than LTD from a platform of the same height without glass. Positive results would indicate that the gerbil seeks tactual cues, and that when these are obtained they are sufficient to determine the descent response.

(3) If both visual and tactual appetition control the $\mathrm{OR}$, then the difference between two platforms presenting different visual, but the same tactual, cues (Prediction 1) should be less than when the platforms differ in both visual and tactual cues. Thus, removing the glass 2 in. from the surface of the high platform should increase the difference in LTD between the two platforms. If descent from one platform is independent of experience on the other platform then LTD from the high platform should be greater when tactual cues (the glass) are not present, while LTD from the low platform should not be affected.

(4) The assumption made in both possible processes that tactual recognition of the lower surface is a necessary condition of descent leads to two predictions: (1) There should be no difference in LTD between a platform somewhat beyond reach of the $O R$ (e.g., 4 in.) and one considerably beyond (e.g., 10 in.). Few Ss should leave either platform. (2) There should be no decline with trials in LTD from the high platforms without a glass sheet within reach of the descent platform.

\section{SUBJECTS}

One hundred and one gerbils (Meriones unguiculatus) were housed individually 24-48 $\mathrm{h}$ before the first day of testing. Of these, 64 (32 males and 32 females) were assigned to four groups and tested at 65.75 days of age. Twenty males, 100-110 days of age, were assigned to a second experiment. Seventeen older ( 360 days) males were later assigned to the replication of one condition. Vibrissae were clipped $24 \mathrm{~h}$ before testing. All Ss were experimentally naive. APPARATUS

Four platforms were constructed from two pieces of wood $(8 \times 3 \times 1 / 2$ in.) connected in the center by a shaft $\left(1 \frac{1}{2} \times 1 \frac{112}{2}\right.$ in.), the length of which determined platform height. Two platforms were $10 \mathrm{in.} \mathrm{in} \mathrm{height,} \mathrm{one} \mathrm{was} 4$ in. high, and one was 2 in. high. Sheets of clear Plexiglas (11 $\times 16 \times 1 / 4$ in.) were mounted to a fixed distance from the upper surface of each platform. In designating platforms, the first number refers to the visual height (floor to upper surface), the second to tactual height (glass to upper surface). The four platforms used were: $2-2,4-4,10-2$, and 10-10.

Platforms were placed in the center of a $41 \times 32$ in. floor covered, except for one condition, by a black, white, and gray checkerboard cloth. The squares were approximately 1 in. on a side. Bright illumination, intended to maximize visual cues, was provided by two $300-W$ floodlights suspended 48 in. above the floor.

\section{PROCEDURE}

Sixteen Ss (eight males and eight females) were assigned to each of the first four platform conditions, the 20100 - to 110-day-old males to the fifth; the 17 360-day-old males were assigned to the replication of the third condition. (1) Visual difference-patterned (V-P). 2-2 and 10-2 platforms were alternated over the checkerboard cloth. These platforms differed only in visual cues. (2) Visual difference-unpatterned (V-U). The same platforms were used as in Group V.P. For this group, however, the floor covering was an unpatterned gray and the floor was surrounded by 15 -in. gray walls to minimize visual cues. (3) Tactual difference (T). 10-2 and $10-10$ platforms over the patterned floor were used to assess the value of tactual cues. This condition was later replicated with the 17 older males. (4) Visual-tactual 
Table 1

Mean Latency to Descend in Minutes (LTD)* and Number of Ss not Descending (NND)

\begin{tabular}{|c|c|c|c|c|c|c|c|c|c|c|c|c|}
\hline \multirow[b]{2}{*}{ Group } & \multicolumn{4}{|c|}{ Day 1} & \multicolumn{4}{|c|}{ Day 2} & \multicolumn{4}{|c|}{ Day 3} \\
\hline & \multicolumn{2}{|c|}{$\begin{array}{l}\text { Platform 1 } \\
\text { LTD NND }\end{array}$} & \multicolumn{2}{|c|}{ Platform 2} & \multicolumn{2}{|c|}{ Platform 1} & \multicolumn{2}{|c|}{ Platform 2} & Platform 1 & $\begin{array}{l}\mathrm{m} 1 \\
\mathrm{NND}\end{array}$ & \multicolumn{2}{|c|}{ Platform 2} \\
\hline $\begin{array}{l}\text { Visual-Patterned (V-P) } \\
N=16\end{array}$ & $\begin{array}{l}2-2 \\
.596\end{array}$ & 1 & $\begin{array}{l}10-2 \\
1.281\end{array}$ & 8 & $\begin{array}{l}2.2 \\
.263\end{array}$ & 0 & $\begin{array}{l}10-2 \\
1.174\end{array}$ & 6 & $\begin{array}{l}2-2 \\
.174\end{array}$ & 0 & $\begin{array}{c}10-2 \\
.858\end{array}$ & 3 \\
\hline $\begin{array}{l}\text { Visual-Unpatterned }(V-U) \\
N=16\end{array}$ & $\begin{array}{l}2-2 \\
1.787\end{array}$ & 13 & $\begin{array}{l}10-2 \\
1.906\end{array}$ & 15 & $\begin{array}{l}2-2 \\
1.523\end{array}$ & 6 & $\begin{array}{l}10-2 \\
1.606\end{array}$ & 12 & $2-2$ & 2 & $\begin{array}{l}10-2 \\
1.019\end{array}$ & 7 \\
\hline $\begin{array}{l}\text { Tactual (T) Younger Ss } \\
\mathrm{N}=15 \\
\text { Older Ss }\end{array}$ & $\begin{array}{l}10-2 \\
1.851\end{array}$ & 12 & $\begin{array}{l}10-10 \\
1.695\end{array}$ & 12 & $\begin{array}{l}10-2 \\
1.723\end{array}$ & 12 & $\begin{array}{l}10-10 \\
1.781\end{array}$ & 13 & $\begin{array}{l}10-2 \\
1.433\end{array}$ & 7 & $\begin{array}{l}10-10 \\
1.619\end{array}$ & 11 \\
\hline$N=17$ & .979 & 7 & 1.703 & 14 & 1.241 & 7 & 1.998 & 16 & 1.005 & 4 & 1.976 & 16 \\
\hline $\begin{array}{l}\text { Visual-Tactual (VT) } \\
N=16\end{array}$ & $\begin{array}{l}2-2 \\
.866\end{array}$ & 5 & $\begin{array}{l}10-10 \\
1.925\end{array}$ & 15 & $\begin{array}{l}2-2 \\
1.059\end{array}$ & 5 & $\begin{array}{l}10-10 \\
1.858\end{array}$ & 13 & $\begin{array}{l}2-2 \\
.875\end{array}$ & 3 & $\begin{array}{l}10-10 \\
1.689\end{array}$ & 10 \\
\hline $\begin{array}{l}\text { VT } 4-10 \\
N=20\end{array}$ & $\begin{array}{l}4-4 \\
1.710 \\
\end{array}$ & 15 & $\begin{array}{l}10-10 \\
1.774 \\
\end{array}$ & 16 & & & & & & & & \\
\hline
\end{tabular}

* Maximum $=2.00 \mathrm{~min}$

differences (VT). 2-2 and 10-10 platforms over the patterned floor were used to assess the relative importance of visual and tactual cues. (5) Visual-tactual difference (VT 4-10). This condition is like VT except that 4-4 and 10-10 platforms were used.

All Ss from the first four groups were tested on three consecutive days, one trial on each platform each day. Order of testing was counterbalanced within each sex. Group VT 4-10 was tested once on each of the two platforms. The Plexiglas sheet was wiped with alcohol after each trial to minimize possible olfactory cues.

For individual test responses, Ss were placed on the upper surface of the platform and left for a maximum of $2 \mathrm{~min}$. Latency to leave the platform (LTD) and number of ORs (defined as a head movement of at least $1 / 2$ in. below the surface) were recorded. If an animal did not leave the platform within $2 \mathrm{~min}$, a score of 2.00 was entered.

\section{RESULTS}

Mean LTDs and number of animals not leaving the platform are recorded for each group in Table 1.

\section{Visual Difference}

The results of separate three-way mixed-model analyses of variance performed on the data for the visua l-pat terned (V-P) and visual-unpatterned (V-U) groups are summarized below. ${ }^{2}$ The platforms effect for Group V-P is highly significant. The platforms effect for Group V.U is also significant; however, inspection of Table 1 reveals that most of the latter difference occurred on Day 3. Analyzing the groups together by means of a four-way between-within design reveals that the Groups by Platforms effect is significant $(F=12.05, \mathrm{df}=1 / 30, \mathrm{p}<.01)$, indicating that the platform effect was stronger in Group V-P than in Group V-U. Also, analysis of data for the first day separately reveals a significant platform effect in Group V-P $(\mathrm{F}=6.13, \mathrm{df}=1 / 15, \mathrm{p}<.05)$ but not in Group V-U (F $=1.97, \mathrm{df}=1 / 15$, $\mathrm{p}>.10$ ). More striking, while only 1 of 16 Ss in Group V-P failed to leave the $2-2$ platform within 2 min on Day 1,13 of $16 \mathrm{Ss}$ in Group V.U failed to descend $\left(\chi^{2}=18.25\right.$, df $=1, p<.001$ ). Thus, Group V-USs failed to discriminate between 2.2 and $10-2$ platforms on Day 1; by Day 3, however, they did discriminate $(F=6.20, \mathrm{df}=1 / 15$, $p<.05)$. The significant days effect indicates that LTD declined with days of testing; the nonsignificant interactions indicate that the decline was equal for the two platforms in both conditions.

These results support Prediction 1: gerbils discriminated between shallow and deep visual heights and responded appropriately. Minimizing visual cues greatly reduced the discrimination.

\section{Tactual Difference}

The results of the tactual group analysis are summarized in Table 1 for the original younger groups of Ss and for the older replication group separately. It will be seen that, for the younger group, the effect for platforms is nonsignificant, indicating that LTD is not under the control of 2 -in. tactual cues; however, the significant Platforms by Days interaction indicates that latencies do decrease with days when 2 -in. tactual cues are available but not when they are not present. An analysis of the data for the two platforms separately reveals that the days effect is significant for the 10-2 platform $(F=3.32, \mathrm{df}=2 / 28, \mathrm{p}<.05)$ but not for the $10-10$ platform $(F=0.96, d f=2 / 28$, $\mathrm{p}>.10$ ). Tactual cues thus exerted only a slight, but significant, control over LTD in this group. Results of the analysis for the replication group of older males reveal a much more striking effect. The platform difference for this group is highly significant. The days effect and Platform by Days interaction for this group are not significant, indicating that the discrimination between platforms was equally present on all 3 days.
These results support Prediction 2: gerbils are able to discriminate between the presence and absence of shallow tactual cues and to respond appropriately.

Visual-T actual Difference

The platforms effect in the visual-tactual (VT) group was highly significant $(F=32.89, d f=1 / 15, p<.001)$. The $10-10$ LTD in Group VT was, as predicted, greater than the 10-2 LTD in Group V-P $(F=19.85$, $\mathrm{df}=1 / 30, \mathrm{p}<.001)$; however, LTD from the 2-2 platform in Group VT was also greater than from the $2-2$ platform in Group V.P $(F=9.37, \mathrm{df}=1 / 30, p<.01)$. This 2-2 platform difference suggests a transfer effect between platforms, with the 10-10 platform inhibiting descent from the 2-2 platform in Group VT, as compared to the effect of the 10-2 platform in Group V.P. The prediction of a greater platforms effect for the visual tactual group rests on the assumption that there should be no 2-2 platform difference between the two groups. Since this assumption is not valid, a comparison between the platforms effects is not meaningful.

\section{Absence of Tactual Cues}

There was no difference in LTD between the $4-4$ and $10-10$ platforms of the visual-tactual $4-10$ group $(F=0.33$ $\mathrm{df}=1 / 19, \mathrm{p}>.10) ; 16$ of $20 \mathrm{Ss}$ on the $10-10$ and 15 of 20 on the $4-4$ platform failed to descend within $2 \mathrm{~min}$. Also, the 10-10 platform days effect was not significant in either Group T or Group VT. This evidence is consistent with the hypothesis that tactual cues are a necessary condition of descent.

$$
\text { DISCUSSION }
$$

The results of the present study indicate that, indeed, the gerbil possesses visual depth discrimination. Tactual cues gained during the orientation response, however, are a necessary condition of descent: the gerbil almost always touches the floor before committing itself, and will not readily descend from a platform higher than the maximum length of the orientation 
response. Tactual cues are also sufficient to control a descent of 2 in. in the absence of shallow visual cues, when they become avallable through lengthening of the orientation response. These findings indicate that during the appetitive phase of descent behavior (the orientation response) both visual and tactual cue-seeking processes are operative. The tactual process is to some degree independent of visual influences.

The much greater tactual discrimination shown by the 17 older Ss in the tactual condition was unexpected. In addition to age, these Ss differed from the other 16 in having been housed for approximately 9 months in standard laboratory group cages. It is possible that such an environment reinforced reliance upon tactual cues. Among the 65- to 75-day-old Ss, visual cues were the primary determinant of descent on early trials. Thus, only three Ss in the visual-unpatterned group left the $2-2$ platform on the first day, while all but one $S$ in the visual-pattemed group descended. Tactual cue-seeking was effective primarily on later trials.
The deep orientation response, and subsequent descent from a 2 -in. height, is thus controlled by at least three factors: prevailing visual cues, appetitive tactual cue-seeking, and previous reinforcement. After reinforcement has occurred, as when shallow visual cues are obtained, the deep orientation response may be considered confirmatory rather than appetitive.

\section{BITTERMAN, M. E., \& WODINSKY, J.} Simultaneous and successive discrimination. Psychological Review, 1953, 60, 371-376.

THIESSEN, D. D., LINDZEY, G., BLUM, S., TUCKER, A., \& FRIEND, H. C. Visual behavior of the Mongolian gerbil (Meriones unguiculatus). Psychonomic Science, 1968, 11, 23-24.

WALK, R. D., \& GIBSON, E. J. A comparative and analytical study of visual depth perception. Psychological Monographs, 1961, 75(Whole No. 519), 1.44.

\section{NOTES}

1. This work was supported by NIMH Grant No. MH 14076-02 and by NIMH Research Development Award MH 11, 174-02 to D. D. Thiessen.

2. A detailed account of the AOV is available upon request.

\section{Chlorpromazine slows decay of visual short-term memory'}

\author{
GEORGE C. STONE, ENOCH CALLAWAY \\ III, REESE T. JONES, and TOM \\ GENTRY, L Langley Porter Neuro- \\ psychiatric Institute, San Francisco, Calif. \\ 94122
}

The effects of chlorpromazine, scopolamine, and pentobarbital on the visual short-term memory trace were studied using Sperling's method. Ss were classified as introverts or extraverts with the Maudsley Test, but this variable had no significant effect. Analysis of variance showed a significant difference among the drug treatments $(p<.05)$. The mean numbers of correct responses for scopolamine, pentobarbital, and placebo, among which there was no significant difference, were pooled and found to differ significantly from the chlorpromazine mean $(p<.01)$. It was concluded that chlorpromazine improved performance either by filtering poststimulus "noise" or by delaying the encoding process for the visual STM trace, thereby making the information available longer.

Sperling's (1960) experiments on visual short-term memory offer an approach to the study of drugs on this initial phase of visual information processing. Chlorpromazine, scopolamine, and pentobarbital all share sedative actions, while chlorpromazine and scopolamine also share anticholinergic action. Yet the drugs are quite dissimilar in other respects-for example, only chlorpromazine is effective in the treatment of schizophrenia. We have therefore undertaken to study the effects of chlorpromazine, scopolamine, and pentobarbital on the decay of visual STM using the Sperling design.

The effects of these drugs on the performance of introverts and extraverts was also examined, in light of the contention by Eysenck (1957) that introverts are less neurally inhibited than extraverts.

\section{METHOD}

Subjects were 40 male medical and dental students, who were paid for their participation in the experiment. Ss were selected from among 65 prospective $S s$ on the basis of the 20 highest and 20 lowest scores on the Extraversion scale of the Maudsley Personality Inventory. Ss were divided into four drug groups of 10, five introverts and five extraverts to a group. Ss in each group received one of the following: chlorpromazine $(50 \mathrm{mg})$, scopolamine $(\mathrm{C} .6 \mathrm{mg})$, pentobarbital $(100 \mathrm{mg})$, or placebo. Drugs were administered in identical capsules and were taken simultaneously by all Ss.

While the drugs were taking effect, Ss filled out information questionnaires and were familiarized with the experimental procedures to be given them. The experiment proper began $45 \mathrm{~min}$ after ingestion of the drugs.

The Ss were seated in the auditorium of Langley Porter Neuropsychiatric Institute at a distance of 23 to $31 \mathrm{ft}$ from a projection screen. Seating position was counterbalanced for drugs and temperaments. Ss were presented with nine-letter ( 3 by 3 ) matrices flashed onto the screen for $1 / 15 \mathrm{sec}$, timed by a Prontor-Press shutter (Ledex, Inc., Dayton, Ohio). Only the 20 consonants were used, to minimize the possibility of the letters' being interpreted as words. Auditory signals were presented by a speaker system at three frequencies $(2500$, $650,250 \mathrm{~Hz}$ ) to indicate which of the three rows of three letters the Ss were to report on the answer sheets provided. The following six time intervals were used, expressed in milliseconds, from termination of flash to onset of tone: $-500,0,100,200,500$, 1000. A PDP-7 computer was programmed to initiate the flash and tone and to set the length of the tone $(500 \mathrm{msec})$.

Subjects were familiarized with the procedure in 24 practice trials. Then, three blocks of 18 presentations were run, with each of the six delays paired with each of the three tones in every block. Thus, each $\mathrm{S}$ had an opportunity to identify 27 letters at each delay. Ss were instructed to guess if they were not sure of the correct let ters and were told to guess different letters, not simply to write XXX. Trials were run approximately every 5 to $10 \mathrm{sec}$, with a short break between blocks. The experiment proper lasted about $10 \mathrm{~min}$.

\section{RESULTS}

The mean number of letters identified by introverts (13.5) and extraverts (14.8) did not differ significantly overall $(\mathrm{F}=2.23$, $\mathrm{df}=1 / 32, \mathrm{p}>.05$ ). The interaction of introversion-extraversion with drugs was not significant either, so Ss were pooled into a single group for each drug.

Figure 1 shows the mean number of correct responses plotted against delay for each treatment. The number of letters from the correct row but reported in the wrong position was found not to exceed chance; therefore, only letters from the indicated row recorded in the proper position were scored as correct responses.

Three-way analysis of variance with repeated measures showed a significant difference among the drug treatments 